\title{
Impact of Hydroxychloroquine on Fructose-induced Metabolic Syndrome in Rats: Promising Protective Effect
}

\author{
Ahmad Shata ${ }^{1,2}$, Mahmoud A. Naga ${ }^{1,3}$, Basem H. Elsawy ${ }^{4,5}$, Abdel-Moneim Hafez ${ }^{6,7 *}$ \\ ${ }^{1}$ Department of Clinical Pharmacology, Faculty of Medicine, Mansoura University, Mansoura, Egypt; ${ }^{2}$ Clinical Pharmacy \\ Department, Faculty of Pharmacy, Delta University for Science and Technology, International Coastal Road, Gamasa City, \\ Mansoura, Dakhaliya, Egypt; ${ }^{3}$ Department of Clinical Pharmacology and Toxicology, AL-Qunfudah Medical College, Umm \\ Al-Qura University, Makkah, Saudi Arabia; ${ }^{4}$ Department of Pathology, Mansoura University, Mansoura, Egypt; ${ }^{5}$ Department of \\ Clinical Laboratory, College of Applied Medical Sciences, Taif University, Kingdom of Saudi Arabia; ${ }^{6}$ Department of Medical \\ Physiology, Faculty of Medicine, Mansoura University, Mansoura, Egypt; ${ }^{7}$ Department of Physiology, College of Medicine, \\ Qassim University, Kingdom of Saudi Arabia
}

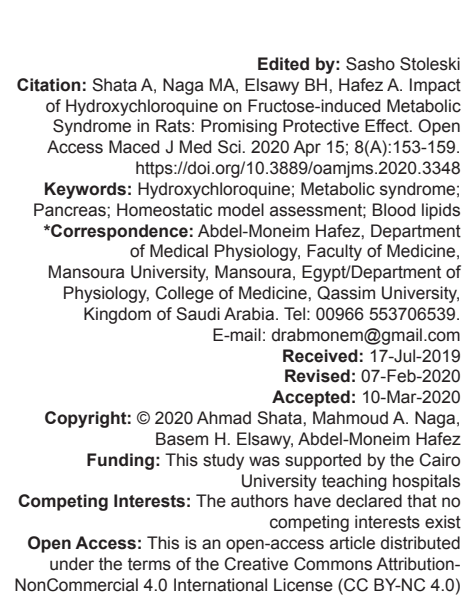

\section{Abstract}

BACKGROUND: Hydroxychloroquine (HCQ) is used in the treatment of malaria and rheumatoid arthritis for a long time. Its effects on inflammation and immune modulation were noted.

AIM: This study aims to investigate the effects of $\mathrm{HCQ}$ in fructose-induced metabolic syndrome and to explore its possible mechanisms.

METHODS AND MATERIALS: Sixty male Sprague-Dawley rats were divided into Group I (negative control), Group II fed on high-fructose diet, and Group III fed on high fructose and subdivided into Group III-a (HCQ $50 \mathrm{mg} / \mathrm{kg}$ ), Group III-b (HCQ 100 mg/kg), Group III-C (HCQ 200 mg/kg), and Group III-d (metformin 100 mg/kg). Body weight, blood glucose, liver enzymes, and lipid profile were measured. Insulin level, homeostatic model assessment (HOMA), soluble-intercellular adhesion molecule, and vascular cell adhesion molecule were assayed. Tumor necrosis facto (TNF)- $\alpha$, adipokines (leptin, resistin, and adiponectin), and histological examination of pancreas were assessed.

RESULTS: HCQ induces good effects on lipid profile and improves significantly HOMA, endothelial stress markers, and adiponectin, and reduces leptin and TNF- $\alpha$ levels. In addition, significant improvement in structural changes was noted in pancreas with different doses of $\mathrm{HCQ}$.

CONCLUSION: Favorable effects of HCQ in fructose-induced metabolic syndrome are promising and can be used early in those at risk of diabetes.

\section{Introduction}

Hydroxychloroquine (HCQ) is one of the famous antimalarial drugs, used also in rheumatic diseases due to its inflammatory and immune modulatory effects [1]. In diabetes mellitus, favorable effects were noted, but mechanisms are not well understood, and no previous experimental studies in metabolic syndrome induced by different agents had investigated its effect [2]. The observations of glucose-lowering side effects in non-diabetic patients have not been clarified yet, but mechanisms were suggested to explain the reduction in serum glucose levels such as increased insulin sensitivity as well as decreased insulin degradation [3]. Accordingly, in clinical scenarios, physicians should check glucose levels in the initial phase. Moreover, HCQ might be applied in rheumatic patients with refractory diabetes difficult to be controlled and rheumatics who are at risk to develop diabetes mellitus [4], [5].
Different adipokine plays a crucial role and represents the link between obesity and insulin resistance (IR). Disturbance in their levels explains largely the underlying mechanisms of metabolic syndrome and diabetes mellitus [6].

Metabolic syndrome is a group of multiple signs and symptoms. It largely increases the risk of diabetes mellitus and heart diseases. The metabolic syndrome consists of central obesity, hypertension, hyperglycemia, and dyslipidemia [7]. Early diagnosis of metabolic syndrome is a great step and the appropriate treatment can lower the risk of diabetes and cardiovascular disease and improve the patients' long-term health [8], [9].

Metformin is one of the most commonly prescribed antidiabetic drugs. It is used as prophylactic therapy in subsets of metabolic syndrome to lessen risk of diabetes and to improve oxidative stress associated with it [10]. Metformin has a marvelous effect in reduction of intestinal absorption of glucose. Furthermore, it increases glucose uptake in the peripheral tissues, especially 
muscle and adipocytes, and decreases hepatic glucose output. Hence, it improves lipid profile and vascular integrity and enhances weight reduction [11], [12].

We hypothesized that $\mathrm{HCQ}$ may have favorable effects on metabolic syndrome, so, the aim of the present work is to assess the protective role of $\mathrm{HCQ}$ with different therapeutic doses if any with comparison with reference drug and to elucidate the underlying mechanisms.

\section{Chemicals}

$\mathrm{HCQ}$ and metformin were obtained from Sigma (Sigma Chemical Co., St. Louis, MO, USA). High-fructose diet was from EL Nasr Pharmaceutical Chem Co., Egypt.

\section{Animals}

Sixty male Sprague-Dawley rats (12 weeks old, weighing 150-160 g) obtained from Mansoura, Faculty of Pharmacy, were used in the study. They were put under the same housing conditions. Rats were housed in a temperature-controlled room under $12 \mathrm{~h}$ light/dark conditions and get ad libitum food and water. All animal experiments were conducted according to the Guide for the Care and Use of Laboratory Animals prepared by Mansoura Medical Research Ethics Committee, Egypt, Code Number R/17.12.181.

\section{Design of the work}

After acclimatization, the rats were randomly allocated into six groups (10 for each):

Group I: Negative control $(n=10)$ fed on a normal diet for 8 weeks and received a normal saline for 4 weeks.

Group II: Fed on a high-fructose diet (60\% fructose) for 8 weeks $(n=10)$ and received a normal saline for 4 weeks [13].

Group III: Fed on high-fructose diet (60\% fructose) for 8 weeks $(n=40)$, then it was subdivided randomly into four equal groups $(n=10)$ :

- Group III-a received HCQ $50 \mathrm{mg} / \mathrm{kg}$ once daily for 4 weeks

Group III-b received HCQ 100 mg/kg once daily for 4 weeks [14].

- Group III-c received HCQ $200 \mathrm{mg} / \mathrm{kg}$ once daily for 4 weeks [14].

Group III-d received metformin $(100 \mathrm{mg} / \mathrm{kg})$ once daily for 4 weeks [15].

\section{Parameters of the study}

Body weight was measured at the start and end of the experiment.

Plasma glucose level was assessed by enzymatic method according to Trinder (1969) [16] using glucose kits (BioMed-Glucose, Hannover, Germany) according to the manufacture instruction.

Insulin was measured by ELISA kits according to the manufacture (DRG International, Inc., New Jersey, USA).

Fasting leptin was determined by ELISA (Linco Research Inc., St. Louis, MO, USA). Furthermore, resistin (Abcam's Rat ELISA) was measured.

Cholesterol was assessed by enzymatic colorimetric method according to Trinder (1969) [16] using cholesterol kits (BioMed-Cholesterol, Hannover, Germany) according to the manufacture instruction.

Plasma high-density lipoprotein cholesterol (HDL-C) level was measured by enzymatic colorimetric method according to Tietz (1976) [17] using HDL-C kits (BioMed-HDL-C, Eng. Chem. for lab technology, Hannover, Germany) according to the manufacture instruction.

Plasma triglycerides (TGs) level was determined by enzymatic colorimetric method according to Fossati and Principe (1982) [18] using TGs kits (BioMed-Triglycerides L.S, Eng. Chem. for lab technology, Hannover, Germany) according to the manufacture instruction.

Plasma low-density lipoprotein cholesterol (LDL-C) level was determined according to Tietz (1976) [17] from equation:

$$
\begin{gathered}
\text { LDL-C }(\mathrm{mg} / \mathrm{dl})=\text { Total } \\
\text { cholesterol - (Triglycerides } \div 5) \text { - HDL-C. }
\end{gathered}
$$

Serum alanine transaminase $(\mathrm{ALT})$ level was determined by enzymatic colorimetric method according to Tietz (1976) [17] using ALT kits (BioMed-ALT, Eng. Chem. for lab technology, Hannover, Germany) according to the manufacture instruction.

Serum aspartate transaminase (AST) level was determined by enzymatic colorimetric method according to Tietz (1976) [17] using AST kits (BioMedAST, Eng. Chem. for lab technology, Hannover, Germany) according to the manufacture instruction.

\section{Adiponectin}

It was analyzed using RayBio Adiponectin ELISA Kit (RayBiotech, Inc., USA), used for quantitative measurement of adiponectin in serum of rat depending on the principle of competitive enzyme immunoassay.

\section{Tumor necrosis factor (TNF)- $\alpha$}

TNF-a (Ray Bio Rat TNF-alpha ELISA Kit Protocol) (Cat\#: ELR TNF alpha-001). It was analyzed using Ray Bio TNF-alpha ELISA Kit (RayBiotech, Inc. USA), used for quantitative measurement of TNF-alpha in serum of rat.

Soluble intercellular adhesion molecule-1 (sICAM-1), soluble vascular cell adhesion molecule 
(sVCAM-1) are estimated by ELISA according to manufacture instruction.

Homeostasis model assessment of IR was measured by homeostatic model assessment $($ HOMA $)=$ (fasting plasma insulin $\times$ fasting plasma glucose) $\div 22.5$; when glucose in $\mathrm{mmol} / \mathrm{l}$ and insulin in $\mathrm{ut} / \mathrm{ml}$ [19]. IR was considered when HOMA >2.6 [20].

\section{Histological procedure}

Immediately after resection of pancreas, it was fixated in $10 \%$ formalin solution. The paraffin blocks were cut at 4-5 $\mathrm{ml}$ thickness. In a blindfold manner, all histological evaluations were performed by a light microscope mounted to digital camera connected to a computer. The presence of cellular injury, such as inflammation or fibrosis, was evaluated. In addition, islet size and the amount of fat in the pancreatic tissue were examined using $\mathrm{H}$ and $\mathrm{E}(\mathrm{H}$ and $\mathrm{E})$-stained slides. The paraffin sections of pancreatic tissue were stained with $\mathrm{H}$ and $\mathrm{E}$ after removing paraffin. Under optical microscope, the histopathological evaluation was performed by a pathologist who was blind with the animal grouping.

Exocrine pancreatic damage was assessed as regard to the presence of congestion, fibrosis, and inflammatory infiltrate in the interstitial tissues and graded by semi-quantitative method ranging from 0 (minimal) to 3 (severe and extensive damage) according to the presence of inflammatory infiltrate, congestion, vacuolization, and fibrosis, and considering the entire exocrine parenchyma on the slide. Islets of Langerhans (IOL) changes including islet shape, intraislet congestion, inflammatory infiltrate, fibrosis, and vacuolization were evaluated [21].

\section{Statistical analysis}

The data were expressed as mean \pm standard deviation (SD). Data were processed and analyzed using the SPSS version 10.0 (SPSS, Inc., Chicago, III., USA). One-way ANOVA was done followed by Tukey's post hoc test. Results were considered significant if $p \leq 0.05$.

\section{Results}

In Table 1, in the present study, HCQ at its different doses (Group III a, b, and c) exerts insignificant reduction of body weight $(p>0.05)$ when compared to Group II, this effect is also seen with Group III-d. In addition, there were a little insignificant effect of tested drugs either HCQ or thiazide on glucose and insulin levels when compared to Group II ( $p>0.05)$. Nonetheless, the effects of tested drugs are more significant as regard HOMA when compared to Group II ( $p<0.05)$.
Table 1: Effect of different doses of $H C Q$ and thiazide on body weight, glucose, insulin, and HOMA (Mean \pm SD)

\begin{tabular}{|c|c|c|c|c|}
\hline Groups & Body weight $\mathrm{g}$ & Glucose $(\mathrm{mmol} / \mathrm{l})$ & Insulin (uU/ml) & HOMA \\
\hline Group I & $172.25 \pm 8.9$ & $5.4 \pm 0.42$ & $5.5 \pm 0.93$ & $1.4 \pm 0.1$ \\
\hline Group II & $183.2 \pm 7.04^{\star}$ & $7.12 \pm 1.24^{*}$ & $7.25 \pm 1.03^{*}$ & $2.61 \pm 0.06^{*}$ \\
\hline Group III-a & $178.75 \pm 4.8$ & $6.3 \pm 1.3$ & $7.4 \pm 1.06^{*}$ & $2.02 \pm 0.12^{*, \#, s}$ \\
\hline Group III-b & $180 \pm 5.01$ & $6.3 \pm 1.03$ & $7.5 \pm 1.1^{*}$ & $2 \pm 0.12^{*, \#, \$}$ \\
\hline Group III-c & $177.75 \pm 4.37$ & $6.6 \pm 1.4$ & $7.75 \pm 0.7^{*}$ & $1.98 \pm 0.16^{*, \#, s}$ \\
\hline Group III-d & $176.5 \pm 4.21$ & $6.4 \pm 1.1$ & $7.25 \pm 0.9^{*}$ & $1.73 \pm 0.07^{\text {*.: }}$ \\
\hline
\end{tabular}

In Table 2, there was significant reduction of cholesterol levels in all tested drugs and significant up increase of HDL of all tested drugs when they compared to Group II ( $p<0.05)$. However, these changes were insignificant as regard TG and LDL ( $p>0.05)$.

Table 2: Effect of different doses of $H C Q$ and thiazide on cholesterol, HDL, TG, and LDL (Mean \pm SD)

\begin{tabular}{|c|c|c|c|c|}
\hline Groups & Cholesterol (mg/dl) & $\mathrm{HDL}(\mathrm{mg} / \mathrm{dl})$ & $\mathrm{TG}(\mathrm{mg} / \mathrm{dl})$ & $\mathrm{LDL}(\mathrm{mg} / \mathrm{dl})$ \\
\hline Group I & $130.13 \pm 4.1$ & $57 \pm 2.8$ & $158.5 \pm 5.86$ & $76 \pm 6.3$ \\
\hline Group II & $212.88 \pm 5.4^{*}$ & $33.88 \pm 5.9^{*}$ & $178.9 \pm 2.8^{*}$ & $113.3 \pm 6^{*}$ \\
\hline Group III-a & $180.63 \pm 10.14^{*, \#}$ & $41.25 \pm 5.03^{* .5}$ & $170.88 \pm 5.69^{*}$ & $108.13 \pm 4.01^{*}$ \\
\hline Group III-b & $177.75 \pm 6.25^{\star, \#}$ & $42.13 \pm 3.64^{* \text {,\# }}$ & $174.5 \pm 4.81^{*}$ & $107.5 \pm 4.75^{\star}$ \\
\hline Group III-c & $178 \pm 6.7^{\text {*\# }}$ & $45.13 \pm 4.42^{*, \#}$ & $176.25 \pm 3.85^{\star}$ & $106.4 \pm 3.4^{*}$ \\
\hline Group III-d & $172.5 \pm 4.5^{\star, *}$ & $48.5 \pm 3.82^{* \text { *\# }}$ & $176.3 \pm 5.6^{*}$ & $109.75 \pm 6.6^{\star}$ \\
\hline
\end{tabular}

In Table 3, all tested drugs have insignificant reduction of liver enzymes as they compared to Group II ( $p>0.05)$.

Table 3: Effect of different doses of HCQ and thiazide on liver enzymes AST and ALT (Mean \pm SD)

\begin{tabular}{lll}
\hline Groups & AST (units/l) & ALT (units/l) \\
\hline Group I & $22.75 \pm 3.45$ & $24.38 \pm 2.1$ \\
Group II & $48.25 \pm 2.5^{*}$ & $51 \pm 5.4^{*}$ \\
Group III-a & $46.88 \pm 2.8^{*}$ & $50.4 \pm 2.9^{*}$ \\
Group III-b & $47.13 \pm 2.6^{*}$ & $49.9 \pm 2.6^{*}$ \\
Group III-C & $46 \pm 3.4^{*}$ & $48.25 \pm 3.05^{*}$ \\
Group III-d & $44.75 \pm 5.6^{*}$., & $48.8 \pm 2.9^{*}$ \\
\hline HCQ: Hydroxychloroquine, ALT: Alanine transaminase, AST: Aspartate transaminase. &
\end{tabular}

In Table 4, all medications were able to exert significant reduction of TNF- $\alpha$, ICAM, and VCAM when compared to Group II ( $p<0.05)$.

Table 4: Effect of different doses of $H C Q$ and thiazide on markers of inflammation (TNF- $\alpha$, soluble ICAMs, and VCAM) (Mean \pm SD)

\begin{tabular}{|c|c|c|c|}
\hline Groups & TNF- $\alpha(\mathrm{ng} / \mathrm{ml})$ & ICAM (ng/ml) & VCAM (ng/ml) \\
\hline Group I & $2.59 \pm 0.24$ & $111.63 \pm 8.1$ & $150.5 \pm 7.9$ \\
\hline Group II & $6.5 \pm 0.51^{\text {*\#\# }}$ & $221.6 \pm 13.98^{*}$ & $187 \pm 5.04^{*}$ \\
\hline Group III-a & $5.7 \pm 0.55^{\star * \#, \$}$ & $181.38 \pm 8.48^{*, \#}$ & $173.25 \pm 6.5^{*, \#}$ \\
\hline Group III-b & $4.9 \pm 0.25^{\text {*:\# }}$ & $178.63 \pm 7.87^{*, \#}$ & $172.75 \pm 6.4^{*, \#}$ \\
\hline Group III-c & $4.6 \pm 0.31^{\text {*\#\# }}$ & $182.38 \pm 8.2^{*, \#}$ & $171.25 \pm 10.6^{\star, \#}$ \\
\hline Group III-d & $4.7 \pm 0.39^{*, \#}$ & $179 \pm 8.4^{*, \#}$ & $172 \pm 8.6^{*, \#}$ \\
\hline
\end{tabular}

In Table 5, HCQ at its different doses beside thiazide decreases significantly leptin when compared with positive control group $(p<0.05)$ with insignificant reduction in resistin levels $(p>0.05)$. As regard adiponectin, all medications given to rats significantly increase it when compared to Group II ( $p>0.05)$.

Table 5: Effect of different doses of $H C Q$ and thiazide on adipokines (leptin, resistin, and adiponectin) (Mean \pm SD)

\begin{tabular}{llll}
\hline Groups & Leptin $(\mathrm{ng} / \mathrm{ml})$ & Resistin $(\mathrm{ng} / \mathrm{ml})$ & Adiponectin $(\mathrm{ng} / \mathrm{ml})$ \\
\hline Group I & $20.4 \pm 2.97$ & $7.62 \pm 1.4$ & $68.3 \pm 3.96$ \\
Group II & $30.75 \pm 3.7^{*}$ & $26.88 \pm 3.4^{*}$ & $44.8 \pm 6.4^{*}$ \\
Group III-a & $19 \pm 2.7^{*}$ & $22.75 \pm 2.4^{*}$ & $57.4 \pm 3.3^{*, \#}$ \\
Group III-b & $18.25 \pm 2.6^{\#}$ & $22.4 \pm 3.5^{*}$ & $60 \pm 3.2^{*, \#}$ \\
Group III-C & $18.12 \pm 2.4^{\#}$ & $23 \pm 3.9^{*}$ & $61.13 \pm 3.3^{*, . \#}$ \\
Group III-d & $17.5 \pm 1.85^{*}$ & $23.4 \pm 3.5^{*}$ & $60.5 \pm 3.9^{*, .}$ \\
\hline HCQ: Hydroxychloroquine. ${ }^{*} \mathrm{p}<0.003,{ }^{*} \mathrm{p}<0.001$ & &
\end{tabular}




\section{Histological results}

The typical view of the IOL was seen in the control group. They were formed of anastomosing cords of epithelial cells surrounded by the exocrine pancreatic acini (Figure 1). The IOL was disrupted in Group II. In many cells, cytoplasm was heterogeneous and vacuolated along with hyperchromatic enlarged nuclei which occasionally disappeared in some cells. In addition, the matrix between the cells was infiltrated by mononuclear cell infiltrate mostly at the periphery of the islets and widened by hyaline deposition (Figure 2). Almost all the cellular components of the IOL were intact with minimal hyaline deposition of the matrix and nearly absent inflammatory cells in all HCQ-treated groups (200, 100, and $50 \mathrm{mg}$, respectively) when compared with Group II. Furthermore, less evident histopathological changes were detected HCQ-treated groups in a dose of $200 \mathrm{mg}$ than HCQ-treated groups in a doses of $100 \mathrm{mg}$ and $50 \mathrm{mg}$ (Figures 3-5).

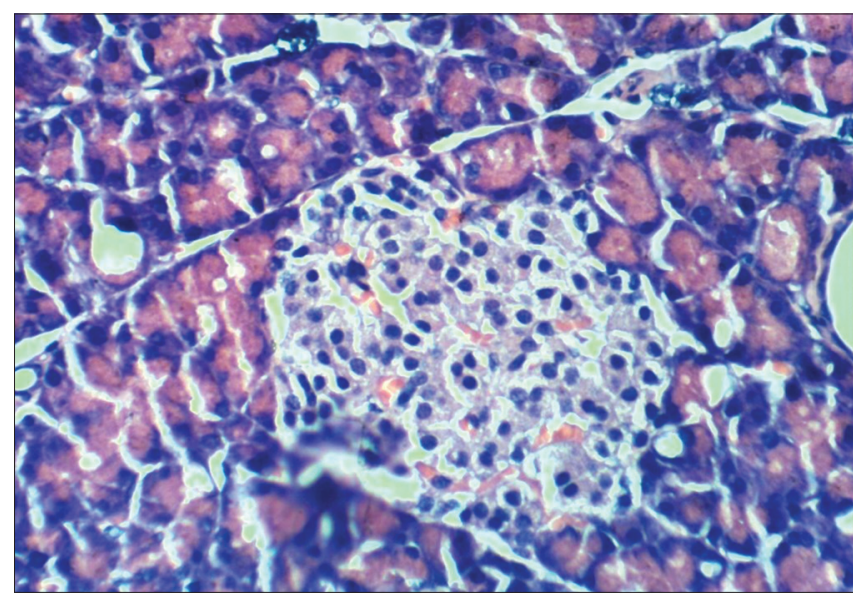

Figure 1: Group 1 (normal control, received $0.5 \mathrm{ml}$ of saline): The islet cells are embedded in normal proportions of the acinar cells that are arranged in lobules $(H$ and $E, \times 100)$.

In the group treated with metformin (Figure 6), preservation of the IOL structure was seen to a wide degree.

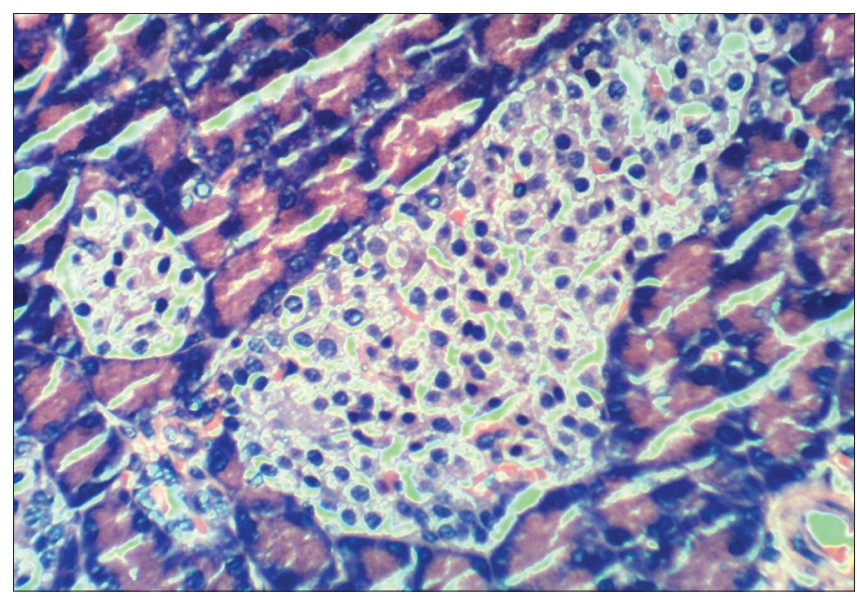

Figure 2: Group II shows mild lymphocytic infiltrate with eosinophilic material in the islets $(H$ and $E, \times 400)$

\section{Discussion}

Metabolic syndrome is a collection of metabolic changes such as hypertension, hyperglycemia, abdominal obesity, dyslipidemia, and IR. It increased gradually over recent years causing high morbidity and mortality [7], [22]. HCQ is widely used drugs in rheumatic diseases and control of malaria. All previous studies discussing only the role of $\mathrm{HCQ}$ in the treatment of diabetes that is associated with rheumatic diseases and occur secondary to it. No other studies evaluate the prophylactic role of $\mathrm{HCQ}$ in risky patients that may develop metabolic diseases like diabetes. In the present

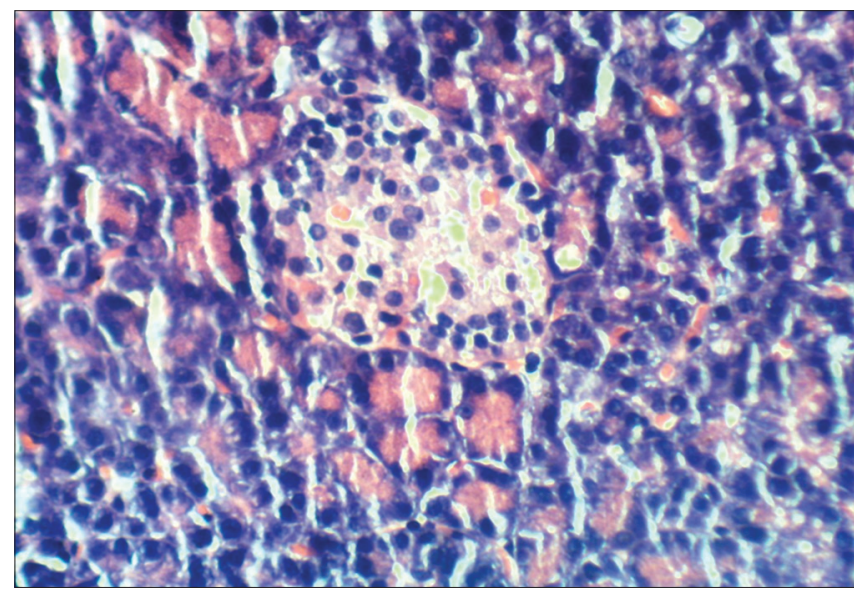

Figure 3: Group III-a (get hydroxychloroquine orally at a dose of $50 \mathrm{mg} / \mathrm{kg} /$ week): Moderate lymphocytic infiltrate with evident vacuolization of the acinar cells ( $H$ and $E, \times 400)$

study, HCQ exerts an ameliorating effect on lipid profile as regard reduction of cholesterol and elevation of HDL. Furthermore, HCQ improves significantly endothelial stress markers and adiponectin and reduces leptin and TNF-a levels. In addition, significant improvement in structural changes was noted in pancreas with different doses of HCQ. Those findings are in

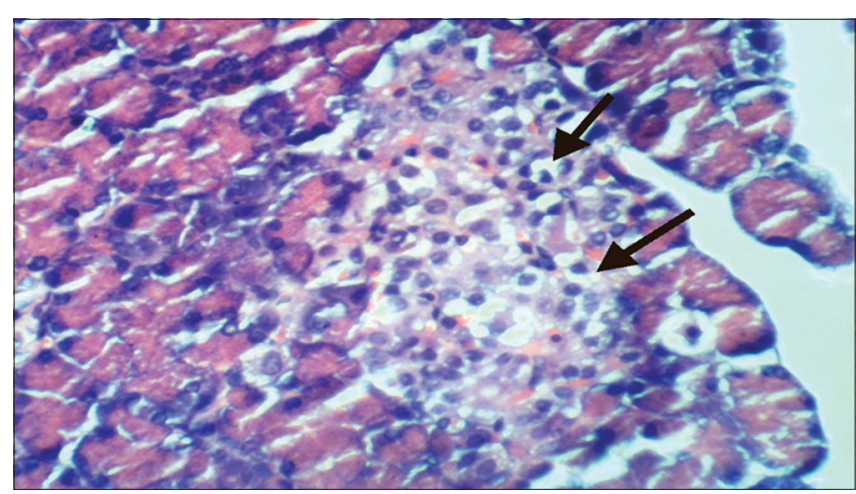

Figure 4: Group III-b (get hydroxychloroquine orally at a dose of $100 \mathrm{mg} / \mathrm{kg}$ ): Mild lymphocytic infiltrate in and around the islets with scattered normal islet cells ( $H$ and $E, \times 400)$

consistent with other studies which hold that $\mathrm{HCQ}$ possibly produces a favorable outcome, may be partly 


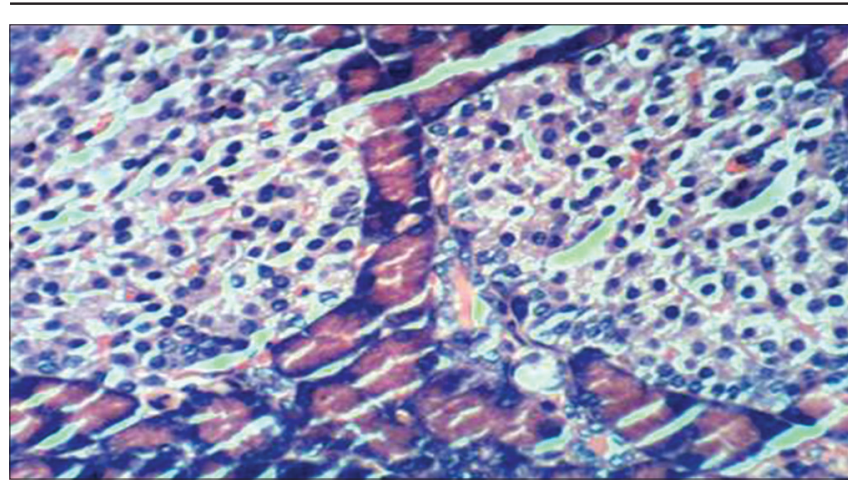

Figure 5: Group III-c (get hydroxychloroquine orally at a dose of $200 \mathrm{mg} / \mathrm{kg}$ ): Small-sized islet cells and scattered lymphocytic infiltrate in the islets surrounded by normal acinar cells ( $H$ and $E, \times 400)$

related to its effects on endothelial stress markers as well as adipokines that usually altered in the presence of IR which considered as initial events in metabolic syndrome. $\mathrm{HCQ}$ can augment insulin action through enhancement of its binding to the receptors in different organs that characterized by initial development of resistance in metabolic syndrome and these events open the way to diabetes later on. In the same way, it alters hepatic metabolism of insulin [23].

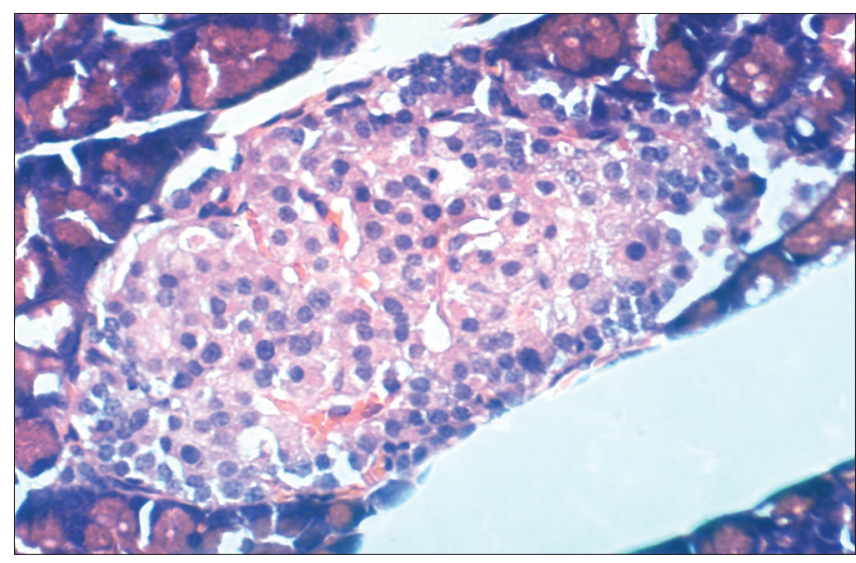

Figure 6: Group III-d (metformin-treated group $100 \mathrm{mg} / \mathrm{kg}$ orally): The IOL structure was preserved with intact cellular component, nearly absent inflammatory cells and minimal hyaline deposition $(H$ and $E$, $\times 400)$

Some studies point that $\mathrm{HCQ}$ may have therapeutic potential in the treatment of type I and type II diabetes. It significantly raised the blood concentration of insulin. This observation may be supported that it may inhibit cytosolic insulin metabolizing enzymes and minimize its degradation [24]. In the same line, other studies document the beneficial impact of $\mathrm{HCQ}$ in correction of different adipokines levels such as leptin, adiponectin, and significant reduction of the vascular endothelial stress markers such as SICAM and sVICAM [25], [26].

Large body of evidence demonstrating a beneficial role of $\mathrm{HCQ}$ in amelioration of lipid profile is present. This effect can be attributed to upregulation of lipid receptors and its immune modulatory effects [27]. On the contrary, other studies do not exhibit any positive changes in lipid profile during $\mathrm{HCQ}$ treatment [28], [29], [30].
In diabetes, the clearance of HCQ significantly increases either through renal and non-renal routes [31] that will affect $\mathrm{HCQ}$ levels in this category of patients. However, HCQ exhibits good impacts on the histological and the metabolic profiles in diabetic patients. Those effects may be partly attributed to its anti-inflammatory action and immune modulation [25].

Anti-inflammatory effects of $\mathrm{HCQ}$ extend to other tissues. In addition, it plays an important role as antiproliferative. This effect may be related to regulation of pro-inflammatory cytokines expression such as TNF- $\alpha$ and inhibition of NF-KB phosphorylation. It also reduces inflammatory neutrophils infiltration. It significantly ameliorates fibrosis in rats with bleomycin-induced pulmonary fibrosis. It inhibits the rat lung fibroblasts proliferation and regulates inflammation [32]. $\mathrm{HCQ}$ reduces the expression of connective tissue growth factor and phosphorylation of extracellular regulated protein kinase (p-ERK) and upregulate Beclin-1, a key regulator of autophagy [33].

The molecular effects of $\mathrm{HCQ}$ can target many subcellular organelles. It prevented the TNF- $\alpha$ induced translocation of NF-KB p65 into the nucleus and the phosphorylation of the p65 subunit. It inhibited the expression of phosphorylated p38 and JNK protein [34]. Furthermore, it substantially reduced TNFa-induced endothelial-leukocyte adhesion and the leukocyte transmigration in pulmonary interstitial tissue. Furthermore, it dramatically inhibited the expression of TNF- $\alpha$-induced endothelial ICAM-1 and VCAM-1 [34].

In other studies, HCQ was studied to relate its effects on neutrophil that plays an important role in inflammation and tissue damage. The authors found that $\mathrm{HCQ}$ reduced neutrophil-derived oxidants [35].

$\mathrm{HCQ}$ plays an important role in the mitigation of fibrosis and tissue remodeling. It promotes a preconditioning like protection in an in vivo simulated rat myocardial ischemia reperfusion injury model through enhancing of phosphorylation of the pro-survival kinase ERK1/2 [36]. It is protective through enhanced phosphorylation of the pro-survival kinase ERK1/2 [36]. It efficiently inhibited hepatic cystogenesis in the polycystic kidney disease and affected the autophagy process that increased in polycystic liver disease [37]. HCQ is evaluated in cardiac neonatal lupus model and it gives favorable results. The authors ascribe this effect due to its effects on diminishing an inflammatory component [38].

\section{Conclusion}

This favorable improvement of metabolic syndrome by $\mathrm{HCQ}$ due to the improvement of lipid profile and adipokines and structural changes in the pancreas pays our attention to make more human 
studies to consider $\mathrm{HCQ}$ as a potential drug in patients who are at risk of metabolic syndrome, particularly at low doses. This promising effects of HCQ can minimize cardiovascular risk in large categories of patients.

\section{References}

1. Hu C, Lu L, Wan JP, Wen C. The pharmacological mechanisms and therapeutic activities of hydroxychloroquine in rheumatic and related diseases. Curr Med Chem. 2017;24(20):2241-9. https://doi.org/10.2174/0929867324666170316115938 PMid:28302011

2. Wang R, Xi L, Kukreja RC. PDE5 inhibitor tadalafil and hydroxychloroquine cotreatment provides synergistic protection against Type 2 diabetes and myocardial infarction in mice. J Pharmacol Exp Ther. 2017;361(1):29-38. https://doi. org/10.1124/jpet.116.239087

PMid:28123046.

3. Sheikhbahaie F, Amini M, Gharipour M, Aminoroaya A, Taheri N. The effect of hydroxychloroquine on glucose control and insulin resistance in the prediabetes condition. Adv Biomed Res. 2016;5(1):145. https://doi.org/10.4103/2277-9175.187401 PMid:27656614

4. Wasko MC, Hubert HB, Lingala VB, Elliott JR, Luggen ME, Fries JF, et al. Hydroxychloroquine and risk of diabetes in patients with rheumatoid arthritis. JAMA. 2007;298(2):187. https://doi.org/10.1001/jama.298.2.187

PMid: 17622600

5. Pilla SJ, Quan AQ, Germain-Lee EL, Hellmann DB, Mathioudakis NN. Immune-modulating therapy for rheumatologic disease: Implications for patients with diabetes. Curr Diab Rep. 2016;16(10):91. https://doi.org/10.1007/s11892-016-0792-9 PMid:27525682

6. Ellulu MS, Patimah I, Khaza'ai H, Rahmat A, Abed Y. Obesity and inflammation: The linking mechanism and the complications. Arch Med Sci. 2017;4(4):851-63. https://doi.org/10.5114/ aoms.2016.58928

PMid:28721154

7. Grundy SM. Pre-diabetes, metabolic syndrome, and cardiovascular risk. J Am Coll Cardiol. 2012;59(7):635-43. PMid:22322078

8. Cornier MA, Dabelea D, Hernandez TL, Lindstrom RC, Steig AJ, Stob NR, et al. The metabolic syndrome. Endocr Rev. 2008;29(7):777-822. PMid: 18971485

9. Alberti KG, Eckel RH, Grundy SM, Zimmet PZ, Cleeman JI, Donato $\mathrm{KA}$, et al. Harmonizing the metabolic syndrome. Circulation. 2009;120(16):1640-5. PMid:19805654

10. Chakraborty A, Chowdhury S, Bhattacharyya M. Effect of metformin on oxidative stress, nitrosative stress and inflammatory biomarkers in Type 2 diabetes patients. Diabetes Res Clin Pract. 2011;93(1):56-62. PMid:21146883

11. Lord JM, Flight IH, Norman RJ. Metformin in polycystic ovary syndrome: systematic review and meta-analysis. BMJ. 2003;327(7421):951-3. https://doi.org/10.1136/bmj.327.7421.951 PMid: 14576245

12. Al Dubayee MS, Alayed H, Almansour R, Alqaoud N, Alnamlah R, Obeid $\mathrm{D}$, et al. Differential expression of human peripheral mononuclear cells phenotype markers in Type 2 diabetic patients and Type 2 diabetic patients on metformin. Front Endocrinol (Lausanne). 2018;9:537. https://doi.org/10.3389/ fendo.2018.00537

PMid:30356719

13. Sánchez-Lozada LG, Tapia E, JiménezA, Bautista P, Cristóbal M, Nepomuceno T, et al. Fructose-induced metabolic syndrome is associated with glomerular hypertension and renal microvascular damage in rats. Am J Physiol Renal Physiol. 2007;292(1):F423-9. https://doi.org/10.1152/ajprenal.00124.2006 PMid: 16940562

14. Pareek A, Yeole P, Tenpe C, Chandurkar N, Payghan R. Effect of atorvastatin and hydroxychloroquine combination on blood glucose in alloxan-induced diabetic rats. Indian J Pharmacol. 2009;41(3):125. https://doi.org/10.4103/0253-7613.55213 PMid:20442820

15. Zayed EA, AinShoka AA, El Shazly KA, Abd El Latif HA Improvement of insulin resistance via increase of GLUT4 and PPARy in metabolic syndrome-induced rats treated with omega-3 fatty acid or I -carnitine. J Biochem Mol Toxicol. 2018;32(11):e22218. https://doi.org/10.1002/jbt.22218

16. Trinder P. Determination of glucose in blood using glucose oxidase with an alternative oxygen acceptor. Ann Clin Biochem Ann Int J Biochem Lab Med. 1969;6(1):24-7.

17. Burtis CA, Ashwood ER, Bruns DE, Tietz NW. Tietz Fundamentals of Clinical Chemistry. Philadelphia, PA: Saunders Elsevier; 2008. p. 952.

18. Fossati $P$, Prencipe L. Serum triglycerides determined colorimetrically with an enzyme that produces hydrogen peroxide. Clin Chem. 1982;28(10):2077-80. https://doi. org/10.1093/clinchem/28.10.2077 PMid:6812986

19. Sun G, Bishop J, Khalili S, Vasdev S, Gill V, Pace D, et al. Serum visfatin concentrations are positively correlated with serum triacylglycerols and down-regulated by overfeeding in healthy young men. Am J Clin Nutr. 2007;85(2):399-404. https:// doi.org/10.1093/ajcn/85.2.399

PMid: 17284735

20. Hettihewa LM, Palangasinghe $S$, Jayasinghe $S S$ Gunasekara SW, Weerarathna TP. Comparison of insulin resistance by indirect methods HOMA, QUICKI and McAuley - With fasting insulin in patients with Type 2 diabetes in Galle, Sri Lanka: A pilot study. Online J Heal Allied Sci. 2006;5(1):1-8. https://doi.org/10.4038/gmj.v12i1.1076

21. Ferreira L, Teixeira-de-Lemos E, Pinto F, Parada B, Mega C, Vala $\mathrm{H}$, et al. Effects of sitagliptin treatment on dysmetabolism, inflammation, and oxidative stress in an animal model of Type 2 diabetes (ZDF rat). Mediators Inflamm. 2010;2010:592760. https://doi.org/10.1155/2010/592760

PMid:20652060

22. Brownlee M. A radical explanation for glucose-induced beta cell dysfunction. J Clin Invest. 2003;112(12):1788-90. https://doi. org/10.1172/jci200320501

PMid: 14679173

23. Bevan A, Christensen J, Tikerpae J, Smith G. Chloroquine augments the binding of insulin to its receptor. Biochem J. 1995;311:787-95. https://doi.org/10.1042/bj3110787 PMid:7487933

24. Emami J, Pasutto FM, Mercer JR, Jamali F. Inhibition of insulin metabolism by hydroxychloroquine and its enantiomers in cytosolic fraction of liver homogenates from healthy and diabetic rats. Life Sci. 1999;64(5):325-35. https://doi.org/10.1016/ s0024-3205(98)00568-2

PMid:10072192

25. Abdel-Hamid AA, El-Firgany AE. Hydroxychloroquine hindering 
of diabetic isletopathy carries its signature on the inflammatory cytokines. J Mol Histol. 2016;47(2):183-93. https://doi. org/10.1007/s10735-016-9664-5

PMid:26872459

26. Batún-Garrido JA, Salas-Magaña $M$, Juárez-Rojop IE Association between leptin and IL-6 concentrations with cardiovascular risk in patients with rheumatoid arthritis. Clin Rheumatol. 2018;37(3):631-7. https://doi.org/10.1007/ s10067-017-3897-x

PMid:29101672

27. Morris S, Wasko M, Antohe J, Sartorius J, Kirchner H, Dancea S, et al. Hydroxychloroquine use associated with improvement in lipid profiles in rheumatoid arthritis patients. Arthritis Care Res (Hoboken). 2011;63(4):530-4.https://doi.org/10.1002/acr.20393 PMid:21452265

28. Tam L, Li E, Lam C, Tomlinson B. Hydroxychloroquine has no significant effect on lipids and apolipoproteins in Chinese systemic lupus erythematosus patients with mild or inactive disease. Lupus. 2000;9(6):413-6. https://doi. org/10.1191/096120300678828541 PMid:10981644

29. Karimifar M, Gharibdoost F, Akbarian M. Triglyceride and highdensity lipoprotein levels as the markers of disease activity and their association with TNF- $\alpha$ and TNF receptor system in systemic lupus erythematosus. APLAR J Rheumatol. 2007;10:221-6. https://doi.org/10.1111/j.1479-8077.2007.00293.x

30. Rossoni C, Bisi M, Keiserman M, Staub H. Antimalarials and cholesterol profile of patients with systemic lupus erythematosus. Rev Bras Reumatol. 2011;51:383-7. https://doi.org/10.1590/ s0482-50042011000400009

PMid:21779713

31. Emami J, Pasutto FM, Jamali F. Effect of experimental diabetes mellitus and arthritis on the pharmacokinetics of hydroxychloroquine enantiomers in rats. Pharm Res. 1998;15(6):897-903.

PMid:9647356

32. Liu L, Ren J, He Z, Men K, Mao Y, Ye T, et al. Cholesterol-modified hydroxychloroquine-loaded nanocarriers in bleomycin-induced pulmonary fibrosis. Sci Rep. 2017;7(1):10737. https://doi. org/10.1038/s41598-017-11450-3

33. Oikarinen A. Hydroxychloroquine induces autophagic cell death of human dermal fibroblasts: Implications for treating fibrotic skin diseases. J Invest Dermatol. 2009;129(10):2333-5. https:// doi.org/10.1038/jid.2009.164

PMid:19749781

34. Li R, Lin H, Ye Y, Xiao Y, Xu S, Wang J, et al. Attenuation of antimalarial agent hydroxychloroquine on TNF- $\alpha$-induced endothelial inflammation. Int Immunopharmacol. 2018;63:2619. https://doi.org/10.1016/j.intimp.2018.08.008 PMid:30121047

35. Jančinová V, Pažoureková S, Lucová M, Perečko T, Mihalová D, Bauerová $\mathrm{K}$, et al. Selective inhibition of extracellular oxidants liberated from human neutrophils a new mechanism potentially involved in the anti-inflammatory activity of hydroxychloroquine. Int Immunopharmacol. 2015;28(1):175-81. https://doi. org/10.1016/j.intimp.2015.05.048

PMid:26071217

36. Bourke L, McCormick J, Taylor V, Pericleous C, Blanchet B, Costedoat-Chalumeau $\mathrm{N}$, et al. Hydroxychloroquine protects against cardiac ischaemia/reperfusion injury in vivo via enhancement of ERK1/2 phosphorylation. PLoS One. 2015;10(12):e0143771. https://doi.org/10.1371/journal. pone. 0143771

PMid:26636577

37. Masyuk Al, Masyuk TV, Pisarello MJ, Ding JF, Loarca L, Huang $B Q$, et al. Cholangiocyte autophagy contributes to hepatic cystogenesis in polycystic liver disease and represents a potential therapeutic target. Hepatology. 2018;67(3):1088108. https://doi.org/10.1002/hep.29577 PMid:29023824

38. Izmirly P, Saxena A, Buyon JP. Progress in the pathogenesis and treatment of cardiac manifestations of neonatal lupus. Curr Opin Rheumatol. 2017;29(5):467-72. https://doi.org/10.1097/ bor.0000000000000414

PMid:28520682 